\title{
ŞÜPHELİ TEKRARLAYAN KARBONMONOKSITT ZEHİRLENMESİ - OLGU SUNUMU
}

\author{
SUSPECTED CARBON MONOXIDE POISONING - CASE REPORT
}

\author{
Ayşegül ŞİMŞEK, Bengüsu MİRASOĞLU*
}

\begin{abstract}
ÖZET
Karbonmonoksit (CO) zehirlenmesi ülkemizde sıkça yaşanmakta olup ciddi bir halk sağlığ problemi oluşturmaktadır. $\mathrm{Bu}$ nedenle genellikle tanı aşamasında kolay akla gelmekle birlikte semptom ve bulguları non-spesifik olduğu için fark edilmeyen ve yanlış tanı konulan olgular da mevcuttur. Olgumuz CO zehirlenmesi nedeniyle Hiperbarik Oksijen tedavisine alınan ve son 1,5 yıldır bir çok kez bayılma, bilinç kaybı nedenleri ile hastaneye başvurmasına rağmen tanı konulamamış olan 51 yaşında kadın hasta ile ilgilidir. Detaylı değerlendirme sonucunda bu bilinç kaybı ataklarının hep banyo sonrası olduğu ancak şimdiye kadar hiç CO zehirlenmesi bakılmadığı fark edilmiştir. Diğer aile bireylerinde görülmemesi de bu durumda etkendir. IGDAS tarafından yapılan bakım ve onarım sonrasında hastanın 3 aylık takiplerinde şikayetleri tekrarlamamıştır. Bu olguda her ne kadar kesin ispat edilememişse de önceki şikayetlerin CO zehirlenmesine bağlı olabileceği düşünülmüş ve non-spesifik baş ağrısı, sersemlik, konsantrasyon güçlüğü, tekrarlayan bayılma gibi şikayetlerin ev içi gizli maruziyet nedeniyle olabileceği, belirtiler açısından bireysel farklılıklar olabileceği vurgulanmak istenmiştir.
\end{abstract}

Anahtar Kelimeler: karbonmonoksit; semptom; hiperbarik

\begin{abstract}
$\mathrm{CO}$ poisoning which is quite common in our country can be a serious health problem. For this reason, it is usually kept in mind on examination but sometimes there may be undiagnosed or misdiagnosed cases due to non-specific signs and symptoms. This case is about a 51 year old female who received hyperbaric oxygen therapy for CO poisoning and had a history of multiple hospital admissions for syncope and loss of consciousness attacks in the last 18 months. A detailed evaluation revealed that these syncope attacks had always been after taking a shower and CO intoxication had not been investigated. In this case, the aim was to direct attention that occult exposure to $\mathrm{CO}$ at home may cause non-specific symptoms and personal behavior can vary.
\end{abstract}

Key words: carbon monoxide; symptoms; hyperbaric

\section{GiRiș}

Karbonmonoksit (CO) yakıt olarak kullanılan, yapılarında karbon bulunan maddelerin yetersiz yanmaları sonucu oluşan renksiz, kokusuz, tatsız bir gazdir $(1,3)$. Zehirlenmenin fizyopatolojisinde temel mekanizma, karbonmonoksitin başta hemoglobin $(\mathrm{Hb})$ olmak üzere hemoproteinlere yüksek affinite ile bağlanması sonucu kanın O2 taşıma kapasitesinin azalması ve hipoksemik hipoksi oluşmasıdır. Diğer bir mekanizma ise CO'in dokularda histotoksik hipoksiye neden olmasıdır. Zehirlenmenin şiddeti, solunan CO miktarına, maruziyet süresine, alveolar ventilasyona ve hastanın özelliklerine göre değişir $(2,5,8)$. Senkop ve kardiyak hasardan hafif baş ağrısı, yorgunluk hissine kadar farklılık gösteren karbonmonoksit zehirlenmesinin belirti ve bulguları non-spesifiktir. Bu nedenle de olguların yaklaşık \%30'unun fark edilmediği ya da yanlış tanı konduğu ve kayıtlı olguların gerçek

\footnotetext{
Date received/Dergiye geldiği tarih: 21.03.2014 - Dergiye kabul edildiği tarih: 05.08.2014

* İstanbul Üniversitesi, İstanbul Tıp Fakültesi, Sualtı Hekimliği ve Hiperbarik Tıp Anabilim Dalı Istanbul (İletişim kurulacak yazar: bengusu.mirasoglu@istanbul.edu.tr)
} 
insidansı yansıtmadığını söylemek mümkündür $(6,7,8)$. Geç dönem sekeller de göz önüne alındığında ciddi bir sağlık problemi ortaya çıkmaktadır (4).

\section{OLGU}

Akut Koroner Sendrom ve Non-ST MI ön tanısı ile hastanemiz Kardiyoloji Anabilim Dalı yoğun bakım ünitesinde yatmakta olan 51 yaşında kadın hasta HBO tedavisi açısından kliniğimize danışıldı. 2 yıldır bilinen hipertansiyon dışında hastalığı olmayan hasta, kliniğimize danışılmasından bir gün önce banyo sonrası senkop öyküsü nedeniyle nedeniyle 112 tarafından en yakın acil servise götürülmüş. Acil servise ulaştığında bilinci kapalı olan hastanın karboksihemoglobin $(\mathrm{COHb})$ düzeyi \%44.9 tespit edilmiş ve başka bir merkezde 1 seans HBO tedavisi almış. Tedavi sonrası bilinci açılan hastanın $\mathrm{COHb}$ düzeyinin \%14,6'ya gerilediği görülmüş. HBO öncesi yapılan tetkiklerinde CK-MB değeri $35 \mathrm{U} / \mathrm{L}$, troponin I değeri $1.251 \mathrm{pg} / \mathrm{ml}$ tespit edilen hastanın EKG'sinde de non-spesifik değişiklikler izlenmesi üzerine hastanemiz kardiyoloji yoğun bakım ünitesine kabul edilmiş. YBÜ'ne yatışından sonra yapılan tetkiklerinde Troponin T 187 $\mathrm{pg} / \mathrm{ml}$ 'den $159 \mathrm{pg} / \mathrm{ml}$ 'e gerilemiş ve arteryel $\mathrm{COHb}$ düzeyi:\%1 olarak ölçülmüş. Bulantı-kusma, baş ağrısı, göğüs ağrısı yakınmaları devam eden ve halen EKG'de non-spesifik değişiklikleri olan hasta tarafımıza danışıldı ve HBO tedavisine devam etmesi uygun bulundu. Hastanın anamnezi derinleștirildiğinde, son 1,5 yıl içinde neredeyse her banyo sonrası senkop yakınması olduğu ve bu nedenle birçok kez hem acile hem de polikliniğe başvurduğu öğrenildi. Fiziki detaylar sorgulandığında şofben banyo içerisinde ve bacalı olduğu bilgisi edinildi. Hasta, genel olarak hep banyoda 15-20 dakika geçirdiğini, bu sefer de diğer günlerden farklı olmadığını belirtti. Bu 1,5 yıllık sürede hiç $\mathrm{CO}$ düzeyi bakılmayan hastanın birçok nörolojik hastalık açısından değerlendirildiği ve yapılan BT, EEG gibi tetkiklerin normal olduğu belirlendi. Diğer aile bireyleri de benzer yakınmalar için sorgulandı ancak banyoda en fazla 15-20 dk kaldıklarını ifade eden aile bireylerinde benzer yakınmaların olmadığı öğrenildi. Kliniğimizde 1 seans daha HBO tedavisi alan hasta, klinik bulguların gerilemesi ve laboratuvar sonuçlarının düzelmesi ile taburcu edildi. Kardiyoloji kliniği tarafından yapılan Koroner Anjiyografisi de normaldi. Olay sonras1 İGDAŞ tarafindan evde yapılan incelemede, banyodaki baca boşluğundan karbonmonoksit sızıntısı tespit edildiği ve gerekli onarımların yapıldığı öğrenildi. Hasta 3 ay süreyle takip edildi ve bu sürede hastada hiçbir yakınma ve bulgu tekrar etmedi.

\section{TARTIŞMA}

Akut CO zehirlenmesi; tanınması göreceli olarak kolay ve klinik tecrübenin fazla olduğu bir acil durumdur. Tanıda çoğu kez COHb düzeyi bakılması yeterli iken, sistemik hasarı değerlendirmek için CPK, LDH, kan şekeri ve metabolik alkaloz araştırması ve kardiak iskemi açısından EKG takibi yapılabilir. Buna rağmen gizli (ve kronik) maruziyetler sonucu oluşan zehirlenmelerde huzursuzluk, yorgunluk hissi ve nezle hali, şiddetli baş ağrısı, baş dönmesi, unutkanlık, bulantı-kusma, karın ağrısı, göğüs ağrısı ve çarpınt1, uyuşukluk ve uyuklama gibi yakınmalar olabilir. Semptomların non-spesifik olması ve her bireyde ayn şekilde ve şiddette görülmemesi nedeniyle, zehirlenmeler grip, gida zehirlenmesi, migren, myokard infarktüsü gibi hastalıklar ile karıșabilmekte ve kimi zaman gözden kaçabilmektedir. Dolayısıyla dikkatli ve detaylı anamnez doğru tanı açısından önemlidir. Ülkemizde özellikle kış aylarında non-spesifik baş ağrısı, sersemlik, konsantrasyon güçlüğü, tekrarlayan bayılma şikayetleri ev içi gizli maruziyet açısından uyarıcı olmalıdır. $\mathrm{COHb}$ düzeyi ile kliniğin korelasyon göstermediği ve zehirlenme eşiğinin bireysel farklılıklar gösterebildiği unutulmamalıdır. Aile bireylerinde benzer şikayetlerin olmaması nedeniyle, bu olguda olduğu gibi tekrarlayan maruziyet sonrası $\mathrm{CO}$ zehirlenmesi dışlanmamalıdır. CO zehirlenmesi şüphesinde hastaya mutlaka rezervuarlı maske ile aralıksı \%100 O2 solutulmalı ve acil HBO endikasyonu var ise hiperbarik oksijen tedavi merkezlerine sevk edilmelidir (6).

\section{KAYNAKLAR}

1. Buckley NA, Juurlink DN, Isbister G, Bennett MH, Lavonas EJ. Hyperbaric oxygen for carbon monoxide poisoning. Cochrane Database Syst Rev. $2011 ;(4)$

2. Garg J, Krishnamoorthy P, Palaniswamy C, Khera S, Ahmad H, Jain D, at al. Cardiovascular abnormalities in carbon monoxide poisoning. Am J Ther. 2014 (Epub ahead of print)

3. Hampson NB, Weaver LK. Carbon monoxide poisoning: a new incidence for an old disease. Undersea Hyperb Med 2007; 34:163-8

4. Raub JA, Mathieu-Nolf M, Hampson NB, Thom SR. Carbon monoxide poisoning - a public health perspective. Toxicology 2000; 145(1):1-14

5. Prockop LD, Chichkova RI . Carbon monoxide intoxication: an updated review. J Neurol Sci. 2007;262(1-2):122-30

6. Metin S, Yıldız Ş, Çakmak T. The role of oxygen therapies in carbon monoxide poisoning. TAF Prev Med Bull 2011; 10(4): 487-94

7. Wu PE, Juurlink DN. Carbon monoxide poisoning. CMAJ 2014;186(8):611 